\title{
A new serotyping method for Klebsiella species: development of the technique
}

\author{
EVE RISER, P. NOONE, AND T. A. POULTON \\ From the Bacteriology Department, Middlesex Hospital Medical School, London W1, and the \\ Department of Microbiology, Royal Free Hospital, London NW3
}

SYNOPSIS A new serotyping method for Klebsiella species using indirect immunofluorescence is des- సु cribed. Nonspecific fluorescence has been minimized by carrying out the capsular antigen-antibody reaction at $\mathrm{pH} 9 \cdot 0$.

Commercial antisera have been tested with the 72 antigenic types of Klebsiella, and appropriate dilutions of each pool and specific antisera have been proposed for use in routine typing. Dilutions were chosen to allow strong fluorescence with each type and its specific antiserum and minimal fluorescence with cross reacting antisera.

Where the pool antisera gave a weak reaction for one or more of the component types, it is recommended that the specific antisera for these types be added to the pool dilution.

The few remaining cross reactions, with the pool and specific antisera in test dilution, are listed in a table. The unique cross reacting patterns of particular types have been found to be useful in identification.

Typing Klebsiella by the fluorescent antibody technique is easy to perform and interpret; the $\stackrel{\varrho}{\varrho}$ results are reproducible, and it is less expensive than the existing capsular swelling method as it is $\unrhd$ more sensitive and requires less concentrated antisera. This new method of typing should facilitate $\overrightarrow{\overrightarrow{0}}$ detailed epidemiological studies of the mode of transmission of Klebsiella species in hospitals and $\exists$ thus allow more effective infection control measures to be instituted.

During the 1960s, Gram-negative bacilli became increasingly important as a cause of hospital infection, as a result of better control and prevention of infection caused by Gram-positive organisms and a true increase in the incidence of Gram-negative sepsis. Klebsiella species have played an especially significant role in this trend. Hospital epidemics have been described, often caused by strains resistant to commonly used antibiotics (Montgomerie et al, 1970; Price and Sleigh, 1970; Finland, 1971; Martin et al, 1971; Selden et al, 1971).

It is difficult to investigate the epidemiology of infections without reliable methods for detecting identical strains of the same species. Phage typing has been invaluable in studying the epidemiology of Staphylococcus aureus sepsis and has greatly facilitated the introduction of measures to terminate or prevent epidemics of infection (Williams et al, 1966), but the application with Klebsiella has been limited

Received for publication 25 November 1975
(Parker, personal communication). So far other $\frac{0}{3}$ typing methods have had limited success in studying the spread of this organism. Bacteriocine typing has been shown to be insufficiently discriminating for

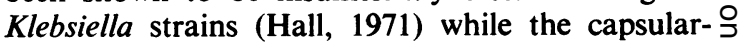
swelling methods developed by Ørskov (1955a), $>$ Kauffmann (1949), and Edwards and Fife (1955) have not become widely adopted, in spite of their N apparent simplicity, except by a few specialist ${ }_{N}^{\circ}$ reference centres.

Capsular swelling is a very subjective test where $\mathrm{\omega}$ the readings can be so ambiguous that only a very우 trained eye can hope to discern a reaction, and eveno experience of the method does not always guarantee $\mathbb{\Phi}$ complete success. Multiple cross reactions have also $\stackrel{?}{+}$ been described (Edwards and Ewing, 1968; Casewell, $\frac{T}{T}$ 1975).

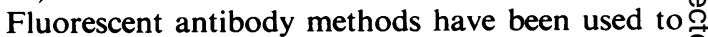
identify many bacteria either directly with a fluores- $\stackrel{\mathbb{Q}}{\varrho}$ cein-labelled (FITC) antiserum or indirectly with a specific antiserum and a labelled conjugate. The use 0 of indirect immunofluorescence to detect specificg्त्र 
capsular antigens of Klebsiella species was complicated by a large number of cross reactions between the 72 antigenic types and the specific antisera. Because of the convenience and availability of the commercial antisera various techniques were employed to try to overcome this difficulty but these proved unsuccessful or impractical. It was then decided to vary the $\mathrm{pH}$ of the incubation of the bacteria with the antisera in view of the possibility that cross reacting antibody may be of low avidity and would be preferentially inhibited by an acidic or alkaline background.

This paper shows how employing $\mathrm{pH} 9.0$ with the fluorescent antibody (FA) method reduces the nonspecific cross reactions, thus allowing this technique to be used for Klebsiella typing. Once the appropriate dilutions of the antisera had been established and the possible cross reactions defined, the FA technique was considered to be a workable method for typing Klebsiella. An evaluation of this method is made in an accompanying paper in this issue.

\section{Material and Methods}

\section{CULTURES}

Reference strains of 72 recognized Klebsiella capsular types were obtained from Dr I. Ørskov, of Statens Seruminstitut, Copenhagen, and were kept at room temperature on nutrient agar slopes. For the experiments, isolates of Klebsiella were subcultured onto Worfel-Ferguson Medium (Difco) for 18-24 hours at $37^{\circ} \mathrm{C}$ to promote capsule production.

\section{SLIDE PREPARATION}

Slides of $0.8 \mathrm{~mm}$ thickness (Microslides, Baird and Tatlock Ltd) were washed in detergent (Pyroneg, Diversey), rinsed thoroughly in tap water, distilled water, and then acetone, and air dried. Ten discrete drops of glycerol were applied to a slide which was then coated with Teflon from an aerosol spray (Fluroplast 82: PTFE spray) and the glycerol was washed off, leaving 10 wells about $2-5 \mathrm{~mm}$ diameter for the bacterial suspension (Chessum, 1970). A medium-sized colony or an equivalent amount from a streak of the culture from the Worfel-Ferguson plate was suspended in about $1 \mathrm{ml}$ of phosphate buffered saline (PBS) at pH 7.2 (Oxoid PBS tablets) and diluted to a density of about 0.03-0.04 at a wave length of $500 \mathrm{~nm}$, yielding an average of 100 bacteria per field at $\times 50$ magnification. Distilled water cannot be used for the suspension as it appears to elute the capsular material from the cell, and there is little fluorescence as a result. Drops of the bacterial suspension were added to the well spaces and allowed to dry; the smears were heat fixed and the slides were stored at room temperature until required.

\section{ANTISERA}

Individual and pool antisera were obtained in powdered form from Difco and, after reconstitution with sterile, distilled water, were stored at $4^{\circ} \mathrm{C}$. Working dilutions were made with Britton Robinson Buffer (BRB), a universal buffer covering a range of pH 2.6-12.0 (McKenzie, 1969) at whatever pH was required using a standard dropper Pasteur pipette. The diluted antisera could be kept at $4^{\circ} \mathrm{C}$ for many weeks and still retain their activity.

A sheep antirabbit globulin fluorescent conjugate (Wellcome) was reconstituted in sterile distilled water and stored in $0.1 \mathrm{ml}$ amounts at $-20^{\circ} \mathrm{C}$. Before use an $0.1 \mathrm{ml}$ aliquot was diluted in $0.9 \mathrm{ml}$ normal saline. This saline solution was kept at $4^{\circ} \mathrm{C}$ and $1 / 40$ working dilutions in PBS were made daily from this (total dilution of 1/400).

\section{ROUTINE FA TECHNIQUE}

Bacterial smears were individually covered with the antiserum, and the slides were placed in an incubation chamber (plastic box) at room temperature for 20 minutes to prevent dehydration, rinsed with tap water for 20 minutes, and air dried at room temperature. A drop of the working dilution of the conjugate was added to each well and incubated at room temperature for 20 minutes. The slides were rinsed again for 20 minutes with tap water, air dried at room temperature, mounted in Polarfluor mountant B (Polaron), and kept at $-20^{\circ} \mathrm{C}$ until read. The fluorescence was observed using a Union Inverted Fluorescence Microscope (Heimer and Taylor, 1972) or a Reichert employing fluorescence-free immersion oil (Polarfluor 8) or Reichert glycerin $\left(n_{D}=1455\right)$ and was graded according to the standard system + to +++ .

\section{ALTERATION OF pH}

Several different antisera which had shown a great deal of cross reaction in preliminary studies were tested against their specific types and several cross reacting strains. The $\mathrm{pH}$ of the initial antigen-antibody reaction was varied from $\mathrm{pH} 5.0$ to $\mathrm{pH} 11.0$ by dilution of the antisera in the appropriate buffer at dilutions of $1 / 20$ to $1 / 160$. This was incubated with the specific and cross reacting bacteria for $20 \mathrm{~min}$ utes and the usual routine method was followed. One to four tests were run with eight different antisera and their corresponding specific types and two to 11 other strains at each $\mathrm{pH}$. The experiments were done in duplicate, triplicate or quadruplicate, and averages were taken for each test as well as an average of all tests for each antiserum.

\section{PHOTOGRA PHY}

The photographs of the bacteria in each set were 
taken at the same magnification, camera settings, and time exposure on an automatic Leitz microscope using Kodak film, Ektachrome-B High speed (EHB 135-20) ASA 125.

\section{TEST OF POOL ANTISERA}

The pool antisera were analysed at dilutions of $1 / 20$ and 1/40 to find the appropriate dilution for typing, ie, the dilution which gave strong fluorescence for each of the pool components while keeping cross reactions at a minimum. Each of the 18 pools was run against each of the 72 types at each dilution and repeated as necessary.

\section{SUPPLEMENTING POOLS}

When a particular type did not react strongly enough with its specific pool, at a dilution favourable to the other pool components, a drop of the specific antiserum of the weak type was added to the pool dilution maintaining a final dilution of $1 / 20$ and $1 / 40$. If necessary, the concentration of the supplemented type was increased until adequate.

\section{CROSS REACTION WITH POOLS}

When the 18 pools were run against the 72 types, the pools that reacted strongly were recorded, and any pool other than the specific pool reacting with a particular type was considered to constitute a cross reaction.

\section{TEST OF SPECIFIC ANTISERA}

Each of the 72 types was tested against its specific antiserum and the type antisera of any pool reacting strongly with it and repeated when necessary. A dilution of $1 / 32$ was used unless the specific antisera were weak, in which case the concentration was increased until adequate for identification.

\section{DILUTION OF SPECIFIC ANTISERA}

When a particular type reacted strongly with other type antisera, these were recorded as cross reactions. The specific and cross reacting antisera were diluted $1 / 64,1 / 128$, and $1 / 256$ until the specific antisera gave a stronger fluorescence than the cross reacting antisera and they could be easily distinguished. This was run in quadruplicate and any necessary repeats were run in duplicate. The remaining antisera which could not be separated by this method were considered to be inherent multiple reactions.

\section{Results}

EFFECT OF PH ON FLUORESCENCE

Figures 1-5 illustrate the effect of pH on the initial antigen-antibody reaction as expressed in the change in fluorescence. The cross reacting types often gave

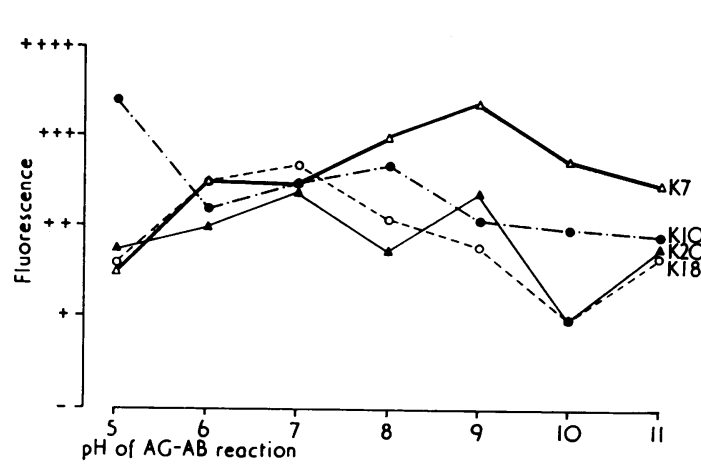

Fig 1 Effect of $p H$ of antigen-antibody reaction on fluorescence of $K 7$ antiserum + specific type $K 7$ and several other strains. Average of two tests, one with three and one with two replicates, dil 1/20.

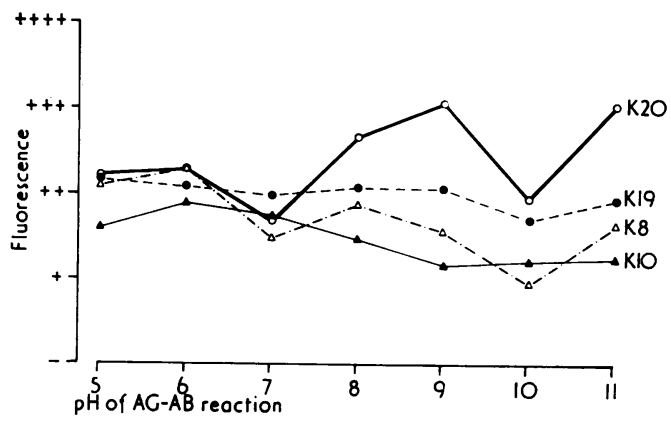

Fig 2 Effect of $\mathrm{pH}$ of antigen-antibody reaction on fluorescence of K20 antiserum + specific type K20 and several other strains. Average of two tests, one with four and one with two replicates, dil 1/40.

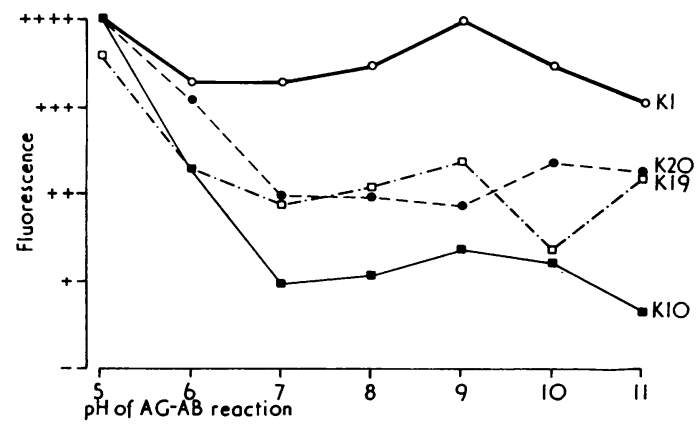

Fig 3 Effect of $\mathrm{pH}$ of antigen-antibody reaction on fluorescence of K1 antiserum + specific type K1 and several other strains. Average of two tests, one with thre and one with four replicates, dil 1/20. 


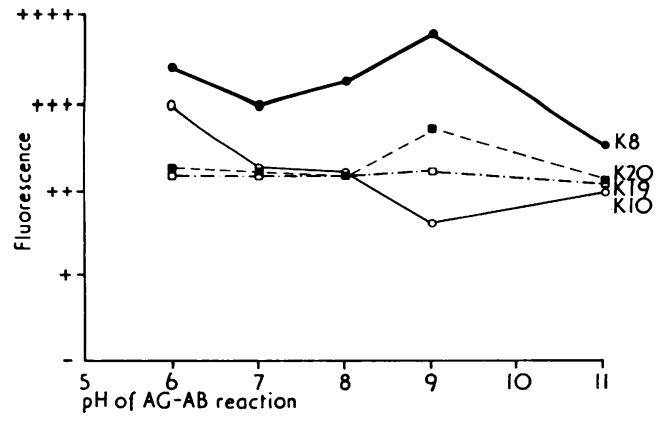

Fig 4 Effect of $p H$ of antigen-antibody reaction on fluorescence of $K 8$ antiserum + specific type $K 8$ and several other strains. One test, average of three replicates dil 1/20.

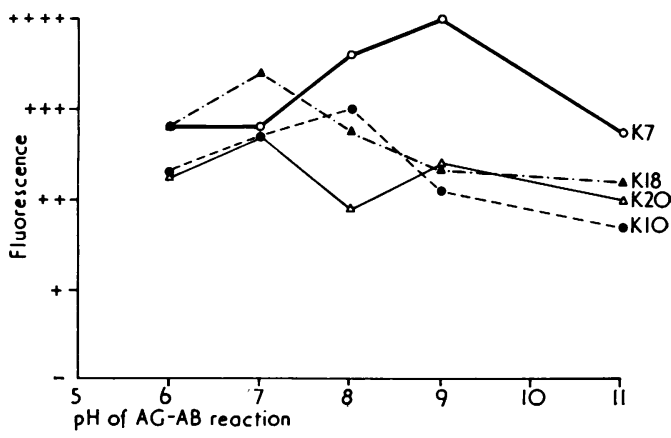

Fig 5 Effect of $p H$ of antigen-antibody reaction on fluorescence of $K 7$ antiserum + specific type $K 7$ and several other strains. One test, average of three repticates, dil 1/20.

fluorescence equal to or greater than that of the specific types from pH 5.0 to $7 \cdot 0$. Non-specific fluorescence decreased with rising $\mathrm{pH}$ (also fig. 6), while the fluorescence of the specific types was enhanced, reaching an optimum at $\mathrm{pH} 9.0$ (also fig. 7). Over the range of $\mathrm{pH} 5.0$ to $\mathrm{pH} 11.0$ the greatest difference between the fluorescence of the specific and non-specific types was observed at $\mathbf{p H ~ 9 . 0 . ~}$

Occasionally, cross reacting strains were still found to give a definite fluorescence at $\mathrm{pH} \mathrm{9.0,} \mathrm{but}$ this could usually be distinguished from specifically reacting strains by the degree of fluorescence. Specific types which gave good $(++++)$ fluorescence at pH 7.0 often displayed a characteristic fluorescence of an even more intense quality at $\mathbf{p H} \mathbf{9 \cdot 0}$.

TEST OF POOL ANTISERA

The majority of the pool components were found to

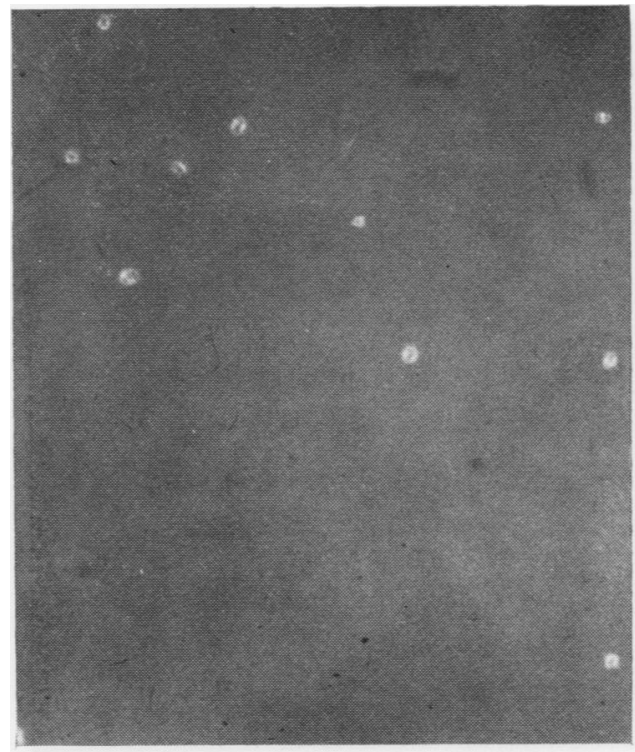

Fig 6a

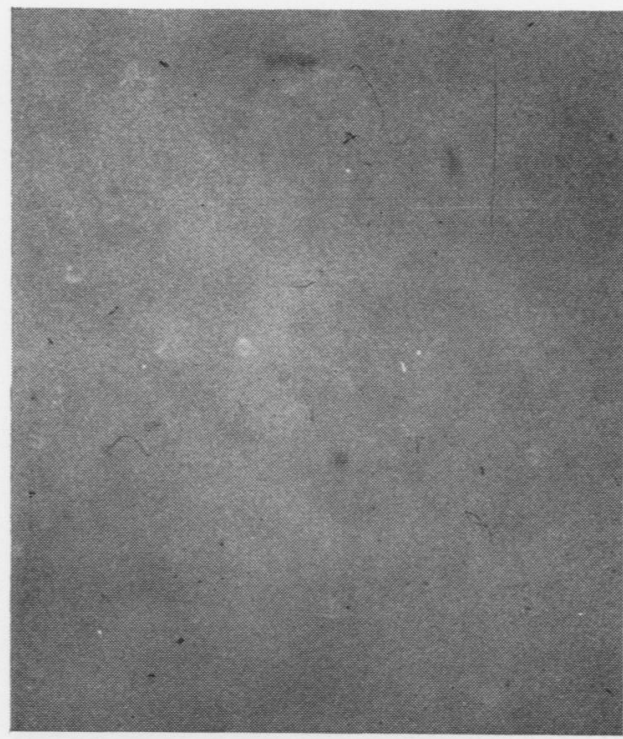

Fig $6 b$

Fig 6 Reduction of fluorescence of cross reacting type from $\mathrm{pH} 7.0$ to $\mathrm{pH}$ 9.0, dil 1/20: (a) antiserum K19 v antigen $\mathrm{K} 10$ at $\mathrm{pH} 7 \cdot 0,{ }_{++++}^{++}$fluorescence; (b) antiserum $K 19$ v antigen $K 10$ at pH 9.0, + + fuorescence.

give optimum fluorescence and a minimum of cross reaction at a dilution of $1 / 40$; therefore, this was chosen as the working dilution for the pool antisera.

SUPPLEMENTING POOLS

Some individual components of the pool antisera did 


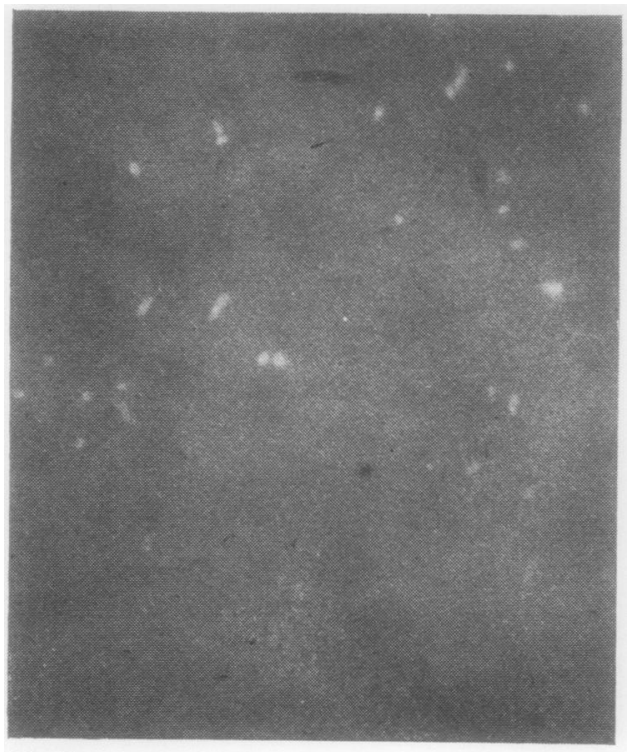

Fig $7 \mathrm{a}$

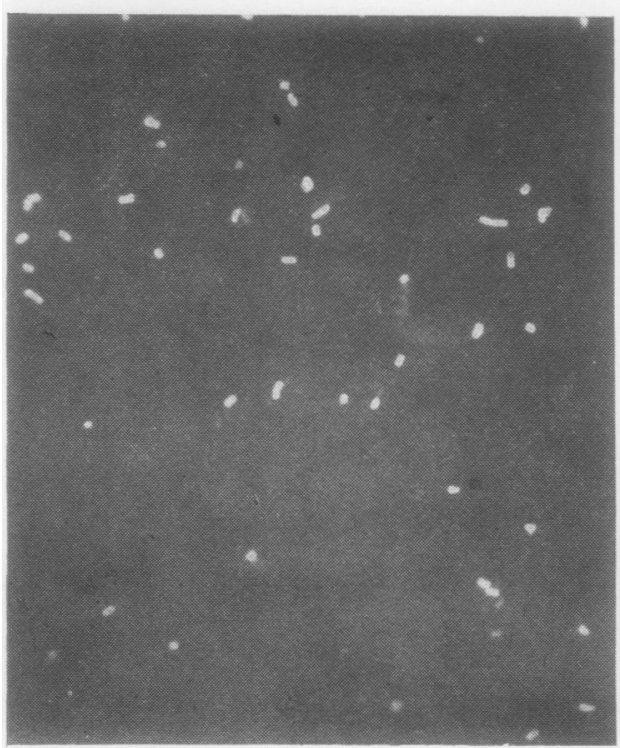

Fig $7 \mathrm{~b}$

Fig 7 Enhancement of fluorescence of a specific type from $\mathrm{pH} 7.0$ to $\mathrm{pH} 9.0$, dil.1/20; (a) antiserum $\mathrm{K} 20 \mathrm{v}$ antigen $\mathrm{K} 20$ at pH 7.0, + + fluorescence; (b) antiserum $K 20 \mathrm{v}$ antigen $\mathrm{K} 20$ at $\mathrm{pH} 9.0,++++$ fluorescence.

not give strong fluorescence at the chosen $1 / 40$ dilution of the pools. The specific antisera of these types were added to this dilution of the pools until appropriate fluorescence was attained. Table I indicates the pools and the specific type antisera with

\begin{tabular}{ll}
\hline Pool & Supplemented Specific Antisera \\
\hline 1 & 3 \\
2 & - \\
3 & - \\
4 & 13,14 \\
5 & 17,19 \\
6 & 11,22 \\
7 & 26,30 \\
8 & 29,40 \\
9 & $-33,36$ \\
10 & $37,39,42^{1}$ \\
11 & 45 \\
12 & 49,50 \\
13 & 55 \\
14 & - \\
15 & 62,63 \\
16 & - \\
17 & - \\
18 & \\
\hline
\end{tabular}

Table I The 18 pool antisera and the specific type antisera with which they are supplemented at a concentration of 1/40 in a 1/40 dilution of the pool

'Supplemented at a concentration of $1 / 20$ in a $1 / 40$ dilution of the pool

which they are supplemented. The type antisera are added at a concentration of $1 / 40$ in a $1 / 40$ dilution of the pool. One exception is pool 11 , which is supplemented with types 37 and 39 at a concentration of $1 / 40$, and type 42 at $1 / 20$.

Casewell $(1972,1975)$ also found that some pools needed to be supplemented in order to obtain a reaction with capsular swelling. Nine of the specific antisera added to the pools for use with fluorescence were also supplemented for use with capsular swelling.

\section{CROSS REACTION WITH POOLS}

At a 1/40 dilution of the supplemented pools, most types fluoresced more strongly with their specific pools than with any other; however, some types gave similar fluorescence with two or more pools, often forming a characteristic pattern for that type. The strongest cross reactions between various pools and a particular type are listed in table II.

TEST OF SPECIFIC ANTISERA

Some cross reaction was found among the 72 types and the various specific antisera of the pools that had reacted strongly with them. Table III lists the specific antisera which react with each type at a 1/32 dilution of the antisera.

Type 27 was the only type which did not react with its specific antiserum but reacted instead with antiserum 46.

DILUTION OF SPECIFIC ANTISERA

Dilutions of $1 / 64$ to $1 / 256$ were found to be adequate to distinguish most of the specific from the cross 


\begin{tabular}{lrl}
\hline Type & Specific Pool & $\begin{array}{l}\text { Pool Antisera giving Positive Reaction at } \\
\text { I/40 Dilution }\end{array}$ \\
\hline 1 & 1 & 1,2 \\
3 & 1 & $1(17)$ \\
7 & 2 & $2(3)$ \\
9 & 3 & $3(4,10)$ \\
10 & 3 & $3(16)$ \\
12 & 8 & $8(3,5,10,11,16,17,18)$ \\
13 & 4 & $8(1,2,4,5,9,11,12)$ \\
20 & 5 & $5(3,10,11,12,16)$ \\
22 & 6 & $6,4,11(5,8,11,16)$ \\
26 & 7 & $7(2,9,10,11,12,15)$ \\
37 & 11 & $11,6,12$ \\
40 & 8 & $8,4,5$ \\
41 & 8 & $8(12)$ \\
42 & 11 & 11,10 \\
43 & 9 & $9(15)$ \\
44 & 9 & 9,5 \\
45 & 12 & $121,5,18(3,4,8,9,10,11,14,16,17)$ \\
46 & 12 & $12(18)$ \\
47 & 12 & $12(14)$ \\
49 & 13 & $13(10)$ \\
50 & 13 & $13(10)$ \\
68 & 17 & $17(1)$ \\
69 & 17 & $17(1)$ \\
\hline
\end{tabular}

Table II Cross reactions of pools with certain specific types: weaker reactions in parentheses

'Background fluoresces with specific antiserum

reacting antisera. Table III indicates the dilutions to be used with multiple antisera reacting with a particular isolate to determine which is the stronger specific antiserum. Those antisera which could not be differentiated are listed in the final column. Weaker reactions are in parentheses.

\section{Discussion}

Many cross reactions have been observed among the capsular antigens of Klebsiella. The cross reactions which occurred with the fluorescent antibody method had previously limited the use of this technique for typing these organisms. The present studies have indicated a relationship between the degree of cross reaction and $\mathrm{pH}$.

The capsular polysaccharides of the Klebsiella serological types have been found to contain uronic acids (Choy and Dutton, 1972) which are often a principal antigenic determinant (Heidelberger and Nimmich, 1972). These influence the specificity of the antigens in which they are present, and when their steric arrangement in different antigens is

Table III Each antigenic type, the specific antisera giving a positive reaction with each type at a dilution of $1 / 32$, the dilution necessary to differentiate cross reacting antisera, and the remaining antisera still giving a strong fluorescence: weaker reaction in parentheses

'Background fluoresces with specific antiserum

\begin{tabular}{|c|c|c|c|}
\hline $\begin{array}{l}\text { Antigenic } \\
\text { Type }\end{array}$ & $\begin{array}{l}\text { Specific Antisera } \\
\text { giving Positive } \\
\text { Reaction at Dilution } \\
1 / 32\end{array}$ & $\begin{array}{l}\text { Dilution } \\
\text { to resolve } \\
\text { Cross } \\
\text { Reactions }\end{array}$ & $\begin{array}{l}\text { Remaining Antisera } \\
\text { giving Positive } \\
\text { Reaction }\end{array}$ \\
\hline 1 & 1 & - & 1 \\
\hline 2 & $2(69)$ & $1 / 128$ & 2 \\
\hline 3 & 3,68 & - & 3,68 \\
\hline 4 & 4 & - & 4 \\
\hline 5 & 5 & - & 5 \\
\hline 6 & 6 & - & 6 \\
\hline 7 & 7,10 & $1 / 64$ & 7 \\
\hline 8 & 8 & - & 8 \\
\hline 9 & 9 & - & 9 \\
\hline 10 & $10,61,7$ & $1 / 128$ & 10 \\
\hline 11 & $11,21(33)$ & $1 / 64$ & 11 \\
\hline 12 & $12,29,42(41)$ & $1 / 256$ & $12(29)$ \\
\hline 13 & $13,12(29,21,30)$ & - & $13,12(29)$ \\
\hline 14 & $14(64,66)$ & $1 / 64$ & 14 \\
\hline 15 & 15 & - & 15 \\
\hline 16 & 16 & - & 16 \\
\hline 17 & 17 & - & 17 \\
\hline 18 & $18(44)$ & $1 / 64$ & 18 \\
\hline 19 & 19 & - & 19 \\
\hline 20 & $20,19,37$ & - & $20,19,37$ \\
\hline 21 & 21,11 & $1 / 128$ & 21 \\
\hline 22 & $22(29,41)$ & $1 / 128$ & 22 \\
\hline 23 & $23,22(37)$ & $1 / 128$ & 23 \\
\hline 24 & 24 & - & 24 \\
\hline 25 & 25 & - & 25 \\
\hline 26 & 26,22 & - & $26^{1}, 22$ \\
\hline 27 & $46(28)$ & $1 / 64$ & 46 \\
\hline 28 & $28^{1}, 27,46$ & $1 / 256$ & 28,27 \\
\hline 29 & $29,42(12)$ & $1 / 128$ & 29 \\
\hline 30 & $30(13)$ & $1 / 64$ & 30 \\
\hline 31 & 31 & - & 31 \\
\hline 32 & 32 & - & 32 \\
\hline 33 & 33 & - & 33 \\
\hline 34 & 34 & - & 34 \\
\hline 35 & 35,33 & $1 / 64$ & $35(33)$ \\
\hline 36 & 36 & - & 36 \\
\hline 37 & 37,22 & $1 / 256$ & 37 \\
\hline 38 & 38 & - & 38 \\
\hline 39 & 39 & - & 39 \\
\hline 40 & $40(17)$ & $1 / 64$ & 40 \\
\hline 41 & $41(12,23,38)$ & $1 / 128$ & $41(12)$ \\
\hline 42 & $42(29)$ & $1 / 64$ & 42 \\
\hline 43 & 43 & - & 43 \\
\hline 44 & 44,18 & $1 / 128$ & 44 \\
\hline 45 & $45(46)$ & - & $45(46)$ \\
\hline 46 & $46^{1}, 27,28$ & $1 / 256$ & 46 \\
\hline 47 & 47 & - & 47 \\
\hline 48 & 48,49 & $1 / 64$ & 48 \\
\hline 49 & 48,49 & $1 / 128$ & 49 \\
\hline 50 & 50 & - & 50 \\
\hline 51 & 51 & - & 51 \\
\hline 52 & 52 & - & 52 \\
\hline 53 & 53 & - & 53 \\
\hline 54 & 54 & - & 54 \\
\hline 55 & 55 & - & 55 \\
\hline 56 & 56 & - & 56 \\
\hline 57 & 57 & - & 57 \\
\hline 58 & 58 & - & 58 \\
\hline 59 & 59 & - & 59 \\
\hline 60 & 60 & - & 60 \\
\hline 61 & 61 & - & 61 \\
\hline 62 & $62(63)$ & - & $62(63)$ \\
\hline 63 & 63 & - & 63 \\
\hline 64 & 64,66 & $1 / 256$ & 64 \\
\hline 65 & 65,64 & - & 65,64 \\
\hline 66 & 66 & - & 66 \\
\hline 67 & 67 & - & 67 \\
\hline 68 & 68 & - & 68 \\
\hline 69 & 69 & - & 69 \\
\hline 70 & 70,72 & $1 / 64$ & 70 \\
\hline 71 & 71 & - & 71 \\
\hline 72 & 72 & - & 72 \\
\hline
\end{tabular}


sufficiently similar, cross reactions take place (Eriksen, 1965).

The uronic acids contain weakly acidic carboxyl groups which are undissociated at a low $\mathrm{pH}$ but almost totally dissociated at a higher $\mathrm{pH}$ (White et $a l, 1968)$. The results of the present studies indicate an increase in specificity with a rise in $\mathrm{pH}$ to $\mathbf{9 \cdot 0}$, and it is possible that this may be due to the greater ionization of the carboxyl groups of the uronic acids. This may be affecting the binding of antibody by changing the structure and charge characteristics of the antigenic site.

A similar use of the effect of $\mathrm{pH}$ is employed by Schmidt and Lennette (1970), who pretreat serum at pH 9.0 for rubella haemagglutination tests to eliminate nonspecific, while fully preserving specific, activity.

Both the pool and specific antisera were improved by conducting the incubation at $\mathrm{pH} 9$. Once the nonspecific fluorescence had been removed it was then possible to investigate the characteristics and limitations of the various antisera.

The pool antisera were found to be inadequate for some of the component types and could be rendered usable only by supplementing them with these particular specific antisera. Casewell $(1972,1975)$ also found that some of the same types had to be added to pool antisera in order to observe capsular swelling. A dilution of $1 / 40$ was chosen for the pool antisera as this gave the best fluorescence of most of the specific types and the least cross reaction. There still remained some cross reactions between the pools at this dilution, although this was generally much weaker and was usually easy to distinguish from the specific pool. Some degree of identification can be made at this stage by the pattern of cross reacting pools for a particular type.

The majority of the type specific antisera gave optimum fluorescence and minimum cross reaction at a dilution of $1 / 32$. Of the cross reactions observed at this dilution $70 \%$ were resolved by further diluting the positive antisera until the specific antiserum gave the greatest fluorescence. Only 13 cross reactions remained among the 72 different types.

One type, type 27 , did not react with its specific antiserum. It has also been observed by Casewell to react with antiserum 46 rather than with its own. There was general interaction among antisera 27, 28, and 46 , but they could be differentiated by use of the two recommended dilutions. There were also mixed cross reactions among antisera $12,13,22,29,41$, and 42 , but each type gave a different cross reacting pattern.

Variations in antisera patterns occasionally occur and should be considered as probably being unique types that are the results of mutation or that have not yet been investigated.

It is not always necessary to dilute the antiser further to separate cross reactions for an identifica $\stackrel{5}{?}$ tion. The cross reacting patterns themselves are usually different, and a tentative identification can be made at that stage by comparison with the table of established cross reactions. The antisera can be diluted further for confirmation.

Cross reactions observed with fluorescence are not: believed to be caused by the presence of somatic anti: bodies in the sera. When antisera of types belonging to $O$ group 1 were absorbed with an acapsulas organism of that group, the same cross reactions? between $O$ group 1 types were still observed. It has also been noted that an organism of a particulart group does not cross react even weakly with the anti sera of all the other types in that group, and the cross reactions are randomly scattered among the 120 \% groups. A bacterium must produce sufficient capsula $\vec{\square}$ material for a reaction to occur, otherwise it may not even react with its specific antiserum, as has beenobserved when using cultures grown on other mediaç

A few specific antisera give better fluorescence at ap higher dilution and should not be missed by anD apparently weak reaction at a dilution of $1 / 32$. The list of cross reactions should be checked to find which antisera to include when the cross reacting antisera may appear slightly stronger at the low dilution. A granular fluorescence of the background can be another aid in identification. This is caused by slime material in the suspension which is produced by some of the types. The slime is of the same constitu= tion as the capsule and gives the same specific reaction with the capsular antisera. It can be so concentratedo as to mask the fluorescence of the bacteria but will be diluted out with a rise in titre, which allows the capsules to appear more brilliant. Although a few crosso reacting antisera have been observed to produce this effect, it is generally specific and will usually indicate? a specific reaction.

The titre of antiserum recommended to distinguish each type is based on several replications of the same batch of serum. Titres obtained for capsular reactions are sensitive to antigen excess (Kauffmann, 1949; Ørskov, 1955b), but careful control of the density of suspension will give reproducible titres? (Casewell, 1975). Casewell also found that serume with different batch numbers gave the same titres on several occasions. Therefore, the titres proposed for ${ }^{+}$ use with fluorescence should be fairly consistent with $\frac{T}{1}$ any batch of antiserum provided the recommended $\frac{\vec{\Phi}}{\mathbb{D}}$ concentration of bacteria is observed.

There are two ways of investigating the reactions $\mathbb{D}$ of the 72 types and the specific antisera. The first is to discover all the types that react with a particularo antiserum, and the second is to find all the antiserao 
that react with a certain type. Each leads to a different set of information which is not necessarily interchangeable. The latter has been chosen to incorporate into the typing method.

It is interesting from a research point of view to know what types cross react with each antiserum, but it is important for typing to know which antisera react with a certain type. When an unkown is being identified, it will react with one or more antisera, and it is more appropriate to check the results quickly against a table arranged for this purpose which will indicate the specific type.

An important characteristic of this typing method is that it gives a consistent typing of identical organisms regardless of pattern, and that it is possible to know exactly which of the patterns is the specific type. This is necessary for a positive identification of isolated strains in any epidemiological study.

The method that has now been developed can be summarized briefly. The bacteria are suspended in PBS and smears are made. To these are added the pool antisera at a dilution of $1 / 40$ to which weaker types have been added at a recommended dilution. The pools are diluted in a buffer at pH 9.0. After the slides have been rinsed and dried, the conjugate is added at a dilution of $1 / 400$ in PBS. The slides are read by grading the degree of fluorescence.

The pools that have given the strongest fluorescence are broken down into their specific antisera which are tested at a dilution of $1 / 32$ at $\mathrm{pH} 9.0$ following the same procedure. When cross reactions exist after this stage, the type may be identified by the pattern of cross reactions of the antisera diluted as recommended to separate them.

\section{Summary of Method}

1 Suspended bacteria in PBS to OD 0.03-0.04 at $500 \mathrm{~nm}$.

2 Make smears and heat fix.

3 Add pool or specific antisera and incubate 20 minutes.

4 Rinse under running tap water 20 minutes.

5 Air dry.

6 Add FITC conjugate and incubate 20 minutes.

7 Rinse under running tap water 20 minutes.

8 Air dry.

9 Mount and store in deep freeze until read.

10 Examine microscopically.

$$
\begin{aligned}
++++ & \text { brilliant fluorescence } \\
+++ & \text { bright fluorescence } \\
++ & \text { definite fluorescence } \\
+ & \text { faint fluorescence } \\
\mathrm{O} & \text { no fluorescence }
\end{aligned}
$$

We wish to express our gratitude to Professor I. M.
Roitt and to Dr F. C. Hay, of the Immunology Department, Middlesex Hospital, for helpful discussion and criticism of the manuscript.

\section{References}

Casewell, M. W. (1972). Experiences in the use of commercial antisera for the capsular typing of Klebsiella species. J. clin. Path., 25, 734-737.

Casewell, M. W. (1975). Titres and cross reactions of commercial antisera for the capsular typing of Klebsiella species. J. clin. Path., 28, 33-36.

Chessum, B. S. (1970). Examination of sera for toxoplasmosis antibody using immunofluorescence. J. med. Lab. Technol., 27, 49-54.

Choy, Y. M. and Dutton, G. G. S. (1972). Occurrence of 3-0$(\beta$-D-glucopyranosyluronic acid)-D-galactose in the capsular polysaccharide of Klebsiella K-type 20. J. Bact., 112, 635-636.

Edwards, P. R. and Ewing, W. H., Eds. (1968). Identification of Enterobacteriaceae, 2nd ed., pp. 217-218. Burgess Publishing Company, Atlanta.

Edwards, P. R. and Fife, M. A. (1955). Studies on the Klebsiella-Aerobacter group of bacteria. J. Bact., 70, 382390.

Eriksen, J. (1965). Immunochemical studies on some serological cross-reactions in the Klebsiella group. 13. Serological investigations of the cross-reaction of Klebsiella type 3 (C), Klebsiella aerogenes strain B. 1076/48 and 'Enterobacter' strain 349. Acta path. microbiol. scand., 64, 527533.

Finland, M. (1971). In Bacterial Infections (Bayer Symposium III, 1970) edited by $\mathbf{M}$. Finland, W. Marget, and K. Bartmann, p. 4. Springer, Berlin and New York.

Hall, F. A. (1971). Bacteriocine typing of Klebsiella spp. $J$. clin. Path., 24, 712-716.

Heidelberger, M. and Nimmich, W. (1972). Additional immunochemical relationships of capsular polysaccharides of Klebsiella and pneumococci. J. Immunol., 109, 1337-1344.

Heimer, G. V. and Taylor, C. E. D. (1972). Improved immunofluorescence obtained with a tungsten lamp in a modified inverted microscope. J. clin. Path., 25, 88-93.

Kauffmann, F. (1949). On the serology of the Klebsiella group. Acta path. microbiol. scand., 26, 381-406.

McKenzie, H. A. (1969). pH and buffers. In Data for Biochemical Research, edited by R. M. C. Dawson, D. Elliott, W. H. Elliott, and K. M. Jones, 2nd ed., p. 485. The Clarendon Press, Oxford.

Martin, C. M., Ikari, N. S., Zimmerman, J., and Waitz, J. A. (1971). A virulent nosocomial Klebsiella with a transferable $\mathbf{R}$ factor for gentamicin: emergence and suppression. $J$. infect. Dis., 124 suppl., S24-29.

Montgomerie, J. Z., Doak, P. B., Taylor, D. E. M., North, J. D. K., and Martin, W. J. (1970). Klebsiella in faecal flora of renal-transplant patients. Lancet, 2, 787-792.

Ørskov, I. (1955a). Serological investigations in the Klebsiella group, 1 . New capsule types. Acta path. microbiol. scand., 36, 449-453.

Ørskov, I. (1955b). Serological investigations in the Klebsiella group, 3. Occurrence of Klebsiella strains in the faeces of normal infants. Acta path. microbiol. scand., 36, 461-470.

Parker, M. T. (Personal communication). Central Public Health Laboratory, Colindale.

Price, D. J. E. and Sleigh, J. D. (1970). Control of infection due to Klebsiella aerogenes in a neurosurgical unit by withdrawal of all antibiotics. Lancet, 2, 1213-1215.

Schmidt, N. J. and Lennette, E. H. (1970). Variables of the Rubella hemagglutination-inhibition test system and their 
effect on antigen and antibody titers. Appl. Microbiol., 19, 491-504.

Selden, R., Lee, S., Wang. W. L. L., Bennett., J. V., and Eickhoff, T. C. (1971). Nosocomial Klebsiella infections: intestinal colonisation as a reservoir. Ann. intern. Med., 74, 657-664.
White, A., Handler, P., and Smith, E. L. (1968). The carbohydrates II. In Principles of Biochemistry, 4th ed., p. 45.으 McGraw-Hill, New York.

Williams, R. E. O., Blowers, R., Garrod, L. P., and Shooter, $\overrightarrow{\vec{F}}$ R. A. (1966). Hospital Infection, 2nd ed., pp. 231-260 Lloyd-Luke, London.

\section{Reports and Bulletins prepared by the Association of Clinical Biochemists.}

The following reports and bulletins are published by the Association of Clinical Biochemists. They may be obtained $\vec{\omega}$ from The Publishing Department, British Medical Journal (ACB Technical Bulletins), B.M.A. House, Tavistock $\stackrel{\circ}{\circ}$ Square, London WC1H 9JR. Overseas readers should remit by British Postal or Money Order.

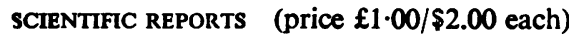

3 Automatic Dispensing Pipettes: an assessment of 35 commercial instruments September 1967 P. M. G. BROUGHTON, A. H. GOIVENLOCK, G. M. WIDDOWSON, and K. A. AHLQUIST

4 An Evaluation of five Commercial Flame Photometers suitable for the Simultaneous Determination of Sodium and Potassium March 1970 P. M. G. BROUGHTON and J. B. DAWSON

SCIENTIFIC REVIEWS (price $£ 1 \cdot 00 / \$ 2.00$ each)

1 The Assessment of Thyroid Function March 1971 F. V. FLYNN and J. R. HOBBS

2 Renal Function Tests Suitable for Clinical Practice January 1972 F. L. MITCHELL, N. VEALL, and R. IV. E. WATTS

3 Biochemical Tests for the Assessment of Fetoplacental Function May 1975 C. E. WILDE and R. E. OAKEY

TECHNICAL BULLETINS (price $£ 1 \cdot 00 / \$ 2.00$ each)

9 Determination of Urea by AutoAnalyzer November 1966 RUTH M. HASLAM

11 Determination of Serum Albumin by AutoAnalyzer using Bromocresol Green October 1967 B. E. NORTHAM and G. M. WIDDOWSON

13 An Assessment of the Technicon Type II Sampler Unit March 1968 B. C. GRAY and G. K. MCGOWAN

14 Atomic Absorption Spectroscopy: an outline of its principles and a guide to the selection of instruments May 1968 J. B. DAWSON and P. M. G. BROUGHTON

15 A Guide to Automatic Pipettes (2nd edition) June 1968 r. M. G. BROLGHTON

16 A Guide to Automation in Clinical Chemistry May 1969 P. M. G. BROUGHTON

17 Flame Photometers: a comparative list of 17 instruments readily available in Britain August 1969 P. WIIDING

19 Spectrophotometers: a comparative list of low-priced instruments readily available in Britain May 1970 C. E. WILOE and P. SEWELL
20 Quantities and Units in Clinical Biochemistry Juneĩ 1970 P. M. G. BROUGHTON

21 Filter Fluorimeters: A comparative list of 18 instru- î ments September 1970 H. BRAUNSBERG and s. s.ळ BROWN

22 Bilirubin Standards and the Determination of Bilirubin by Manual and Technicon AutoAnalyzer Methods $\frac{D}{O}$ January 1971 BARBARA BILLING, RUTH HASLAM, and N. WALD

23 Interchangeable Cells for Spectrophotometers andō Fluorimeters September 1971 S. S. BROWN and A. 11. GOIVENLOCK

24 Simple Tests to Detect Poisons March 1972 B. w. MEADE et $\mathrm{cll}$.

25 Blood Gas Analysers May 1972 K. DIxoN

26 Kits for Enzyme Activity Determination September 1972 S. B. ROSALKI and D. TARLOW

27 Assessment of Pumps Suitable for Incorporation into Existing Continuous Flow Analytical Systems November 1972 A. FLECK et al.

28 Routine Clinical Measurements of Transferrin in Human Serum September 1973 k. DIXON

29 Control Materials for Clinical Biochemistry (5thi edition) September 1973 J. F. STEVENS

30 Notes on the Quality of Performance of Serum Cholesterol Assays September 1973 s. s. BRowN

31 Determination of Uric Acid in Blood and in Urine음 July 1974 R. W. E. WATTS

32 A Survey of Amino Acid Analysers Readily Avail- 0 able in the United Kingdom September 1974 J. E.N CARLYLE and P. PURKISS

33 Definitions of some Words and Terms used in Automated Analysis November 1974 A. FLECK, R. ROBINSON, S. S. BROWN, and J. R. HOBBS

34 Measurement of Albumin in the Sera of Patients $\stackrel{D}{\rightarrow}$ January 1975 LINDA SLATER, P. M. CARTER, and J. R. HOBBS

35 Investigation of the Validity of Temperature Cor-市 rection Factors for Serum Aspartate and Alanine Trans. $\frac{O}{\mathbb{D}}$ aminases March 1975 s. B. ROSALKI et al.

36 Factors Influencing the Assay of Creatinine, November 1975 J. G. H. COOK 